\title{
Safety of users in road evacuation: modelling and DSS for transport supply and supply-demand interaction
}

\author{
A. Vitetta, G. Musolino \& F. A. Marcianò \\ LAST, Laboratory for Transport Systems Analysis DIMET, \\ Department of Computer Science, Mathematics, Electronics and \\ Transportation, Mediterranea University of Reggio Calabria, Italy
}

\begin{abstract}
In the last two decades several Decision Support Systems (DSS) implementing transport modelling have been developed to support transport planning in ordinary conditions. However, especially since $9 / 11$, great efforts have been made to adapt the existing DSS, on the one hand, and develop dedicated DSS, on the other, to simulate transportation systems in emergency conditions in order to support evacuation planning and/or operative stages. Nowadays, several DSS are available on the market, or have been developed as research prototypes, for the above purpose.

In this paper, based upon a comprehensive literature review, a selection of DSS are analysed and compared according to their ability to support evacuation planning activities. An application is set up to test transport system simulation through a DSS implementing a microscopic DTA model in order to support evacuation planning. The objective is to test the response capabilities of a DSS in supporting the validation of procedures to be undertaken in the event of emergency evacuation. The aim of the work is to provide planners, technicians and agencies with detailed understanding of the potential and shortcomings of modelling and DSS currently available both on the market and in research.
\end{abstract}

Keywords: DSS for evacuation planning, supply, demand-supply interaction. 


\section{Introduction}

Disasters are classified as natural, such as hurricanes, floods and wildfires, and man-made, such as terrorist attacks, chemical spills and nuclear accidents. In response to them, risk assessment [1] and evacuation planning [2] have become increasingly relevant to rescuing human lives.

The time schedule concerning the occurrence of a generic disaster may be characterized by time instants (figure 1):

- $\mathrm{t}_{0}$ emergency planning activities start;

- $\mathrm{t}_{1}$ disaster occurrence is notified or forecast;

- $t_{2}$ the disaster occurs and starts its effects;

- $\mathrm{t}_{3}$ system vulnerability starts to change;

- $\mathrm{t}_{4}$ system vulnerability stops changing.

With reference to the above time schedule, there are two main activities:

- evacuation planning, inside the time interval $\left[\mathrm{t}_{0} ; \mathrm{t}_{1}\right)$, concerning the identification, simulation and validation of evacuation procedures to be implemented in the case of occurrence of different types of disasters;

- operative stage, inside the time interval $\left[t_{1} ; t_{4}\right)$, concerning the organization and execution of evacuation procedures to be implemented due to the occurence of a specific disasters.

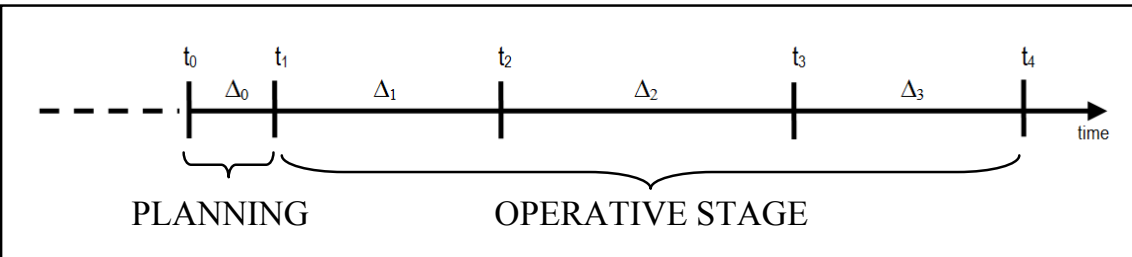

Figure 1: $\quad$ Time schedule of disaster occurrence and human activities.

Evacuation planning is carried out in ordinary conditions with reference to different potential disasters whose characteristics may only be supposed (occurence time, location, impact area size, magnitude, duration, ...). The operative stage starts after the disaster is notified, whose characteristics are known (occurence time, location, impact area size) while others may be reasonably predicted (magnitude, duration). The operative stage has a shorter time lag to be executed than evacuation planning. According to the length of the time lag available for management activities, evacuation may be:

- $\quad$ preordered, when the available time lag is long enough to allow evacuation procedures to be implemented (i.e. inform the population as regards departure times, destinations, transport modes and paths);

- $\quad$ emergency, when the available time lag is so short (or does not exist) that no evacuation procedure can be implemented.

Today several Decision Support Systems (DSS) able to simulate transportation systems in emergency conditions in order to support evacuation 
planning and/or the operative stage are available on the market or have been developed as research prototypes. They were originally developed to simulate transportation systems in ordinary conditions and then adapted to the above purpose.

In this paper, selected DSS are analysed and compared according to their ability to support evacuation planning. The work was carried out during a twoyear research project called SICURO, set up by the Laboratory for Transport Systems Analysis (LAST) of the Mediterranea University of Reggio Calabria (Italy). The objective of SICURO was to develop models and guidelines to simulate evacuation demand [3], supply and demand-supply interaction [4-6], path design for emergency vehicles [7] and pedestrian outflow in a building [8].

Of the many case studies of evacuation planning supported by existing DSS, the most significant papers according to the transport model adopted in the DSS are as follows: macroscopic [9, 10], microscopic [11, 12] and mesoscopic [13, 14].

Both evacuation planning and the operative stage may be effected using macro, meso and micro models. The choice of a modelling approach is conditioned by the spatial scale of analysis, the desired/necessary aggregation of output data, and the time lag available before the disaster's occurrence. For example, in the event of the operative stage for emergency evacuation, a short time lag could suggest the use of a macro model, which ensures a swift modelling response, albeit with an aggregated level of output data.

Based upon a comprehensive literature review $[15,16]$, the analysed DSS are compared according to criteria such as supply model, demand-supply interaction (assignment) model, user needs, performance indicators and ITS functions. The aim of the work is to provide planners, technicians and agencies with detailed understanding of the potential and shortcomings of modelling and DSS currently available both on the market and in research.

\section{Modelling and DSS}

The existing DSS supporting evacuation planning may adopt static or dynamic traffic assignment models to simulate demand-supply interaction. Static Traffic Assignment (STA) models simulate a transportation system in stationary conditions. Dynamic Traffic Assignment (DTA) models remove static model assumptions, allowing transportation system evolution to be represented. DTA models can be analysed according to the characteristics of the link model adopted. In particular, link flow representation can be continuous or discrete and cost functions can be aggregate or disaggregate. DTA models can be classified into macroscopic, mesoscopic and microscopic.

Macroscopic models use continuous flow representation and cost functions with aggregate variables (speed, density, flow) and with explicit capacity such as in static models. The representation of space and time can be continuous or discrete. Microscopic and mesoscopic models are based on discrete flow representation allowing simulation of the behaviour of groups of users (termed packages) or of a single user. Cost functions are aggregated for mesoscopic 
models and disaggregated for microscopic models in which the traffic flow is the result of individual choices, interactions among users and interactions between users and road facility.

In the following section a selection of DSS is analysed and compared in order to evaluate their ability to support evacuation planning activities.

\subsection{User needs}

According to the general objective concerning the simulation of a transport system in emergency conditions to support evacuation planning, there are several user needs that a DSS must satisfy:

- estimation of indicators (link indicators; demand-supply interaction indicators; evolution indicators, for the analysis of transport system evolution during evacuation);

- input needs (key parameters can be user-defined; integration with other models; integration with other databases and Geographic Information Systems (GIS); graphical network builder; graphical animation of results;

- ITS functions (signal optimization, ramp metering, variable message signs, etc.).

\subsection{DSS}

In table 1 the DSS are classified by the following model characteristics:

- modelling traffic assignment, which can be static (STA) or dynamic (DTA) with relative approach (meso or micro);

- supply model, which indicates if link and node cost function specification is fixed or it can be chosen among different given alternatives or it can be user defined;

- assignment, which represents the type (or types) of models for transport supply-demand interaction simulation.

Table 2 presents the capability of each DSS in estimating the values of different indicators that support evacuation planning. These indicators are classified into link, demand-supply interaction and system evolution indicators. They should provide a clear and detailed description of transport system evolution, allowing the effectiveness of different evacuation plans to be assessed. DSS are classified in table 3 as regards input needs, considering for example the possibility of changing key parameters and integration with other software. DSS are presented in table 4 in terms of their capability to simulate different ITS functions. These functions can improve network performance through advanced transport information systems (such as variable message signs and route guidance) or real time supply design operations (such as ramp metering and contra-flow), thereby optimizing traffic flow on the network.

\subsection{Comparison between DSS and user needs}

Macro models are able to support the transport system simulation of extended urban areas or regions, because the output data provided matches the level of aggregation required and computational times are relatively short. 
Table 1: $\quad$ DSS classification: supply and demand-supply interaction models.

\begin{tabular}{lccccc}
\hline \multirow{2}{*}{ DSS } & \multirow{2}{*}{ APPROACH } & \multicolumn{2}{c}{ SUPPLY MODEL } & \multicolumn{2}{c}{ DEMAND-SUPPLY INTERACTION } \\
\cline { 3 - 6 } & & LINK & NODE & PATH CHOICE & ASSIGNMENT \\
\hline Emme/2 [17] & STA & $\mathrm{V}$ & -- & $\mathrm{S}$ & NL-UE-SO \\
TransCAD [18] & STA & $\mathrm{F}$ & -- & S, PT & NL-UE-SO \\
MT Model [19] & STA & $\mathrm{V}$ & -- & S-D & NL-UE \\
VISUM [20] & STA & $\mathrm{V}$ & $\mathrm{F}$ & S, PT & NL-UE-SO \\
OmniTRANS [21] & STA & $\mathrm{V}$ & $\mathrm{V}$ & S-D, PT & NL-UE \\
Cube Avenue [22] & meso & -- & -- & S, ER & WD \\
DYNASMART [23] & meso & $\mathrm{V}$ & $\mathrm{V}$ & PT-ER & WD \\
TransModeler [24] & STA & $\mathrm{V}$ & $\mathrm{V}$ & S, PT & UE \\
DynaMIT [25] & meso-micro & & & S, PT & WD \\
DSS SICURO [26] & meso & -- & -- & S-D, PT & WD \\
AIMSUN [27] & meso & $\mathrm{V}$ & -- & S-D, PT-ER & WD \\
INTEGRATION [28] & micro & F & $\mathrm{V}$ & D, PT & WD \\
MITSIMLab [29] & micro & $\mathrm{F}$ & $\mathrm{F}$ & S, PT-ER & WD \\
PARAMICS [30] & micro & $\mathrm{V}$ & $\mathrm{V}$ & S, PT & WD \\
VISSIM [31] & micro & $\mathrm{V}$ & -- & S, PT & WD
\end{tabular}

APPROACH: STA=Static Traffic Assignment, meso=mesoscopic Dynamic Traffic Assignment, micro=microscopic Dynamic Traffic Assignment; LINK/NODE: V=cost function specification can be chosen among different given alternatives or it can be user defined, $\mathrm{F}=$ cost function specification is fixed, --=not-stated; PATH CHOICE: $\mathrm{S}=$ stochastic, $\mathrm{D}=$ deterministic, PT=pre-trip, ER=en-route; ASSIGNMENT: $\mathrm{NL}=$ network loading, $\mathrm{UE}=$ user equilibrium, $\mathrm{SO}=$ system optimum, $\mathrm{WD}=$ within day dynamic.

This is fundamental especially in the case of a short available time period for evacuation planning (or operative stage), when it is necessary to support the decision process with quantitative data, albeit of an aggregate type.

Table 2: $\quad$ DSS classification: indicators.

\begin{tabular}{llllllllllll}
\hline \multicolumn{1}{c}{ DSS } & $\mathrm{L} 1$ & $\mathrm{~L} 2$ & $\mathrm{~L} 3$ & $\mathrm{~L} 4$ & $\mathrm{DS} 1$ & $\mathrm{DS} 2$ & $\mathrm{DS} 3$ & $\mathrm{DS4}$ & $\mathrm{DS5}$ & $\mathrm{E} 1$ & $\mathrm{E} 2$ \\
\hline Emme/2 & $\mathrm{X}$ & $\mathrm{X}$ & $\mathrm{X}$ & -- & $\mathrm{X}$ & $\mathrm{X}$ & $\mathrm{X}$ & $\mathrm{X}$ & -- & -- & -- \\
TransCAD & $\mathrm{X}$ & $\mathrm{X}$ & $\mathrm{X}$ & -- & -- & -- & $\mathrm{X}$ & $\mathrm{X}$ & -- & -- & -- \\
MT Model & $\mathrm{X}$ & $\mathrm{X}$ & $\mathrm{X}$ & -- & -- & $\mathrm{X}$ & -- & $\mathrm{X}$ & -- & -- & -- \\
VISUM & $\mathrm{X}$ & $\mathrm{X}$ & $\mathrm{X}$ & -- & $\mathrm{X}$ & $\mathrm{X}$ & $\mathrm{X}$ & $\mathrm{X}$ & $\mathrm{X}$ & $\mathrm{X}$ & -- \\
OmniTRANS & $\mathrm{X}$ & $\mathrm{X}$ & $\mathrm{X}$ & $\mathrm{X}$ & -- & -- & -- & -- & -- & -- & -- \\
Cube Avenue & $\mathrm{X}$ & $\mathrm{X}$ & $\mathrm{X}$ & $\mathrm{X}$ & -- & -- & -- & - & $\mathrm{X}$ & $\mathrm{X}$ & -- \\
DYNASMART & $\mathrm{X}$ & $\mathrm{X}$ & $\mathrm{X}$ & $\mathrm{X}$ & $\mathrm{X}$ & $\mathrm{X}$ & $\mathrm{X}$ & $\mathrm{X}$ & $\mathrm{X}$ & $\mathrm{X}$ & -- \\
TransModeler & $\mathrm{X}$ & $\mathrm{X}$ & $\mathrm{X}$ & $\mathrm{X}$ & $\mathrm{X}$ & $\mathrm{X}$ & $\mathrm{X}$ & $\mathrm{X}$ & $\mathrm{X}$ & -- & -- \\
DynaMIT & $\mathrm{X}$ & $\mathrm{X}$ & -- & $\mathrm{X}$ & -- & -- & -- & $\mathrm{X}$ & -- & -- & -- \\
DSS SICURO & $\mathrm{X}$ & $\mathrm{X}$ & -- & $\mathrm{X}$ & -- & -- & $\mathrm{X}$ & $\mathrm{X}$ & -- & $\mathrm{X}$ & $\mathrm{X}$ \\
AIMSUN & $\mathrm{X}$ & $\mathrm{X}$ & $\mathrm{X}$ & $\mathrm{X}$ & $\mathrm{X}$ & $\mathrm{X}$ & $\mathrm{X}$ & $\mathrm{X}$ & $\mathrm{X}$ & $\mathrm{X}$ & -- \\
INTEGRATION & $\mathrm{X}$ & $\mathrm{X}$ & $\mathrm{X}$ & -- & $\mathrm{X}$ & $\mathrm{X}$ & $\mathrm{X}$ & $\mathrm{X}$ & $\mathrm{X}$ & $\mathrm{X}$ & $\mathrm{X}$ \\
MITSIMLab & $\mathrm{X}$ & $\mathrm{X}$ & -- & -- & $\mathrm{X}$ & $\mathrm{X}$ & $\mathrm{X}$ & $\mathrm{X}$ & $\mathrm{X}$ & -- & -- \\
PARAMICS & $\mathrm{X}$ & $\mathrm{X}$ & $\mathrm{X}$ & $\mathrm{X}$ & -- & -- & -- & -- & -- & -- & -- \\
VISSIM & $\mathrm{X}$ & $\mathrm{X}$ & $\mathrm{X}$ & $\mathrm{X}$ & $\mathrm{X}$ & $\mathrm{X}$ & $\mathrm{X}$ & $\mathrm{X}$ & $\mathrm{X}$ & -- & -- \\
\hline
\end{tabular}

LINK INDICATORS: L1=flow, L2=average speed, L3=flow/capacity, L4=queue length; DEMAND-SUPPLY INTERACTION INDICATORS: DS1=average travel distance per vehicle, DS2=total travel distance, DS3=average travel time per vehicle, DS4=total travel time, DS5=average speed on the network; SYSTEM EVOLUTION INDICATORS: E1=number of vehicles on the network, $\mathrm{E} 2=$ number of vehicles that reach each destination; --=not-available or not-stated.

By contrast, meso and micro models provide output data which are more disaggregated than macro models even if this requires higher computational times and resources.

Meso and micro models are useful for detailed transport system analysis, allowing the effectiveness of different evacuation plans to be assessed on the basis of a large quantity of disaggregate data. Moreover, several meso and micro models offer the possibility to simulate ITS functions that are fundamental in evacuation planning. In all cases, the choice of one model rather than another 
Table 3: $\quad$ DSS classification: input needs.

\begin{tabular}{|c|c|c|c|c|c|}
\hline DSS & 1 & 2 & 3 & 4 & 5 \\
\hline Emme/2 & $\mathrm{X}$ & $\mathrm{X}$ & $\mathrm{X}$ & $\mathrm{X}$ & $\mathrm{X}$ \\
\hline TransCAD & -- & -- & $\mathrm{X}$ & -- & $\mathrm{X}$ \\
\hline MT Model & $\mathrm{X}$ & -- & -- & -- & $\mathrm{X}$ \\
\hline VISUM & $X$ & $\mathrm{X}$ & $\mathrm{X}$ & $\mathrm{X}$ & $\mathrm{X}$ \\
\hline OmniTRANS & $\mathrm{X}$ & $\mathrm{X}$ & $\mathrm{X}$ & $\mathrm{X}$ & -- \\
\hline Cube Avenue & $\mathrm{X}$ & $\mathrm{X}$ & $\mathrm{X}$ & -- & $\mathrm{X}$ \\
\hline DYNASMART & $\mathrm{X}$ & $\mathrm{X}$ & -- & -- & $\mathrm{X}$ \\
\hline TransModeler & $\mathrm{X}$ & $\mathrm{X}$ & $\mathrm{X}$ & -- & $\mathrm{X}$ \\
\hline DynaMIT & -- & $\mathrm{X}$ & -- & -- & -- \\
\hline DSS SICURO & $\mathrm{X}$ & -- & -- & $\mathrm{X}$ & $\mathrm{X}$ \\
\hline AIMSUN & $\mathrm{X}$ & $\mathrm{X}$ & $\mathrm{X}$ & $\mathrm{X}$ & $\mathrm{X}$ \\
\hline INTEGRATION & $\mathrm{X}$ & - & - & - & $\mathrm{X}$ \\
\hline MITSIMLab & $\mathrm{X}$ & -- & -- & -- & $\mathrm{X}$ \\
\hline PARAMICS & $\mathrm{X}$ & $\mathrm{X}$ & -- & $\mathrm{X}$ & $\mathrm{X}$ \\
\hline VISSIM & $\mathrm{X}$ & $\mathrm{X}$ & $\mathrm{X}$ & $\mathrm{X}$ & $\mathrm{X}$ \\
\hline
\end{tabular}

Information System, 4=Graphical Network Builder, 5=Graphical Animation of Results; --=not-available or not-stated.

depends on user experience and skill as regards the different evacuation planning objectives and characteristics (spatial scale and available time period).

Table 4: DSS classification: ITS functions.

\begin{tabular}{llllllllllllllll}
\hline \multicolumn{1}{c}{ DSS } & 1 & 2 & 3 & 4 & 5 & 6 & 7 & 8 & 9 & 10 & 11 & 12 & 13 & 14 & 15 \\
\hline Emme2 & -- & -- & -- & -- & -- & -- & -- & -- & -- & -- & -- & -- & -- & -- & -- \\
TransCAD & $\mathrm{X}$ & -- & -- & -- & -- & -- & -- & -- & -- & -- & -- & -- & -- & -- & -- \\
MT Model & -- & -- & -- & -- & -- & -- & -- & -- & -- & -- & -- & -- & -- & -- & -- \\
VISUM & -- & -- & -- & -- & -- & -- & -- & -- & -- & -- & -- & -- & -- & -- & -- \\
OmniTRANS & $\mathrm{X}$ & $\mathrm{X}$ & $\mathrm{X}$ & $\mathrm{X}$ & -- & -- & -- & -- & -- & -- & -- & -- & -- & -- & -- \\
Cube Avenue & $\mathrm{X}$ & $\mathrm{X}$ & -- & -- & -- & -- & $\mathrm{X}$ & -- & -- & -- & -- & -- & -- & -- & $\mathrm{X}$ \\
DYNASMART & -- & $\mathrm{X}$ & $\mathrm{X}$ & -- & $\mathrm{X}$ & -- & $\mathrm{X}$ & $\mathrm{X}$ & -- & -- & -- & -- & -- & -- & $\mathrm{X}$ \\
TransModeler & -- & -- & $\mathrm{X}$ & -- & $\mathrm{X}$ & -- & $\mathrm{X}$ & -- & -- & -- & $\mathrm{X}$ & -- & -- & -- & $\mathrm{X}$ \\
DynaMIT & $\mathrm{X}$ & $\mathrm{X}$ & -- & -- & $\mathrm{X}$ & $\mathrm{X}$ & $\mathrm{X}$ & $\mathrm{X}$ & $\mathrm{X}$ & $\mathrm{X}$ & -- & $\mathrm{X}$ & -- & -- & $\mathrm{X}$ \\
DSS SICURO & -- & -- & -- & -- & -- & -- & -- & -- & -- & -- & $\mathrm{X}$ & -- & -- & -- & $\mathrm{X}$ \\
AIMSUN & $\mathrm{X}$ & $\mathrm{X}$ & $\mathrm{X}$ & $\mathrm{X}$ & $\mathrm{X}$ & $\mathrm{X}$ & $\mathrm{X}$ & $\mathrm{X}$ & -- & -- & -- & -- & $\mathrm{X}$ & -- & $\mathrm{X}$ \\
INTEGRATION & $\mathrm{X}$ & $\mathrm{X}$ & $\mathrm{X}$ & $\mathrm{X}$ & $\mathrm{X}$ & -- & $\mathrm{X}$ & $\mathrm{X}$ & -- & $\mathrm{X}$ & -- & $\mathrm{X}$ & $\mathrm{X}$ & -- & -- \\
MITSIMLab & $\mathrm{X}$ & $\mathrm{X}$ & $\mathrm{X}$ & $\mathrm{X}$ & $\mathrm{X}$ & -- & $\mathrm{X}$ & $\mathrm{X}$ & -- & -- & -- & $\mathrm{X}$ & $\mathrm{X}$ & -- & $\mathrm{X}$ \\
PARAMICS & -- & $\mathrm{X}$ & $\mathrm{X}$ & $\mathrm{X}$ & $\mathrm{X}$ & $\mathrm{X}$ & $\mathrm{X}$ & $\mathrm{X}$ & -- & -- & -- & $\mathrm{X}$ & $\mathrm{X}$ & -- & -- \\
VISSIM & -- & $\mathrm{X}$ & $\mathrm{X}$ & $\mathrm{X}$ & $\mathrm{X}$ & $\mathrm{X}$ & $\mathrm{X}$ & $\mathrm{X}$ & -- & $\mathrm{X}$ & $\mathrm{X}$ & $\mathrm{X}$ & $\mathrm{X}$ & -- & -- \\
\hline
\end{tabular}

1=Signal optimization; $2=$ Co-ordinated traffic signals; $3=$ Adaptive traffic signals; $4=$ Priority to public transport vehicles; $5=$ Ramp metering; $6=$ Zone access control; $7=$ Variable message signs; $8=$ Route guidance; $9=$ Parking guidance; $10=$ Public transport information; $11=$ Support for pedestrians and cyclists; $12=$ Probe vehicles; $13=$ Vehicle detectors; $14=$ Contraflow/lane reversal; 15=Incidents; --=notavailable or not-stated.

\section{Application}

The application set out to test a transport system simulation through a DSS implementing a microscopic DTA model to support evacuation planning. The aim was to test the response capabilities of a DSS in supporting the validation of procedures to be implemented in the event of emergency evacuation.

The application consisted in reproducing in the lab the whole set of technical operations (called STEPS) that are required to simulate the transport system through the DSS in a specific evacuation scenario during an operative stage. The objective was to estimate a range of minimum and maximum times (lower and upper bounds) required for each technical operation. 
The application was performed with reference to a disaster occurrence simulated during a real evacuation experiment conducted at the test site of Melito Porto Salvo (Reggio Calabria, Italy). The simulated disaster was that of a truck leaking hazardous freight with a risk of explosion. Further details are reported in [4-6].

The STEPS are identified and described as regards the worst conditions for which the operator has to execute each of them separately, using independent resources. It is assumed that the operator is an expert user of the DSS and the main input files (constructed according to the characteristics of the transportation system in ordinary conditions) are ready to be launched or be modified. The sum of the times provides the temporal upper bound of the procedure.

STEP 1 - SUPPLY DESIGN. From the knowledge of the truck position on the network, it is necessary to define the size of the impact area and identify the modifications (such as road closure and contraflow) that must be considered. The operator has to modify input files related to the road network (constructed as regards the characteristics of the unmodified supply in ordinary conditions) in order to reproduce supply modifications. This step takes 5-10 minutes.

STEP 2 - HISTORICAL TRAVEL DEMAND ESTIMATION. Through an historical travel demand database, the operator estimates the origin-destination matrices and the historical travel demand time profile. This step takes about 5 minutes.

STEP 3 - EVACUATION TRAVEL DEMAND ESTIMATION (exogenous input from other tasks). From the knowledge of impact area size, another group of operators simultaneously estimates the evacuation travel demand and the relative time profile through modelling and dedicated DSS. These data are transferred to the operator to complete demand input files. This step takes about 1 minute because the computational time for evacuation travel demand estimation is very short. However, if the time spent estimating evacuation travel demand is higher than the time spent performing STEP 1 and STEP 2, also this step will be longer.

STEP 4 - SUPPLY-DEMAND INTERACTION SIMULATION. Once the input files are completed, the DSS can be launched. This step takes 5-10 minutes.

STEP 5 - INDICATOR ESTIMATION AND ANALYSIS. Once the simulation is performed, the provided output data feed indicator estimation (link, demandsupply interaction and evolution indicators). Some indicators can be calculated and reproduced in a graphical way by elaborating output through other software (like EXCEL). This step takes 30-40 minutes.

STEP 6 - RISK ASSESSMENT. The operator calculates the area under the time profile of the number of vehicles that reach the refuge area, which is a measure of the system exposure in relation to the time evolution (figure 2). If for the tested evacuation scenario an arrival time of the last evacuated vehicle, $t_{p}[5,6]$, is predicted to be higher than the instant of time when system vulnerability stops changing (and nobody can be rescued), $\mathrm{t}_{4}[5,6]$, the operator calculates, using other software, the area between $t_{4}$ and $t_{p}$ representing a measure of disaster magnitude (figure 3). This step takes 10-20 minutes. 
For testing the effectiveness of an evacuation scenario through the use of the DSS about 50-85 minutes is required. This time represents the upper bound, in the worst conditions, if the operator has to perform each of them separately using independent resources. This means that if the operator has to test a number of evacuation scenarios he/she must spend 50-85 minutes on each of them.

Finally, in the case of a completely automatic procedure and several operators testing different evacuation plans simultaneously, the optimum solution can be found in a few minutes. Given that, during the observed real experiment, evacuation procedures started 11 minutes after notification of the disaster, this means that, in the best conditions, DSS can also be used for the operative stage of emergency evacuation.

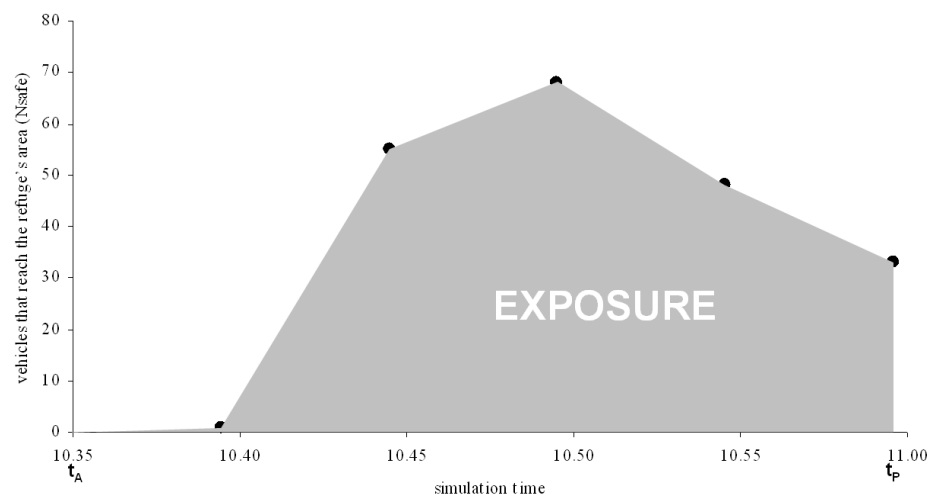

Figure 2: $\quad$ Number of vehicles reaching the refuge area vs. time.

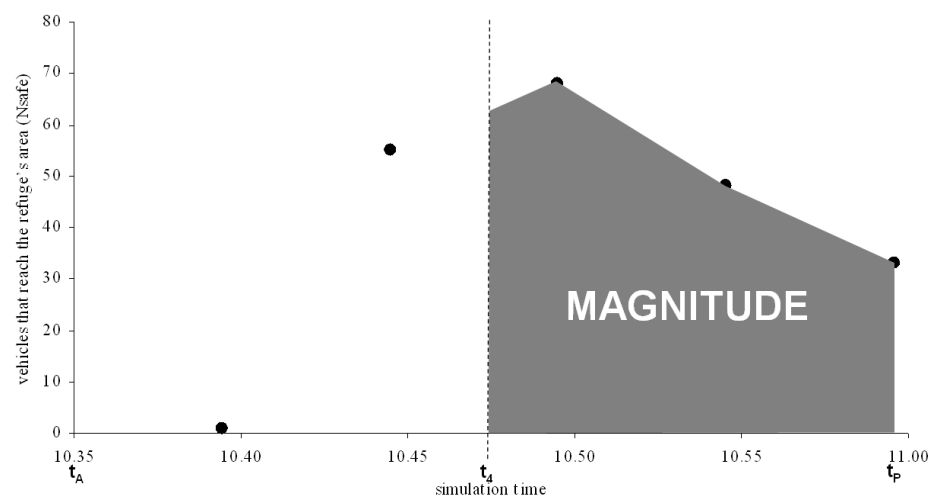

Figure 3: $\quad$ System exposure and example of disaster magnitude.

\section{Conclusions}

In the last two decades several DSS, primarily developed to support transport planning in ordinary conditions, have been adapted or developed to support 
evacuation planning and/or operative stages as well. In this paper some selected DSS were analysed and compared as to their capability to support evacuation planning. The aim of the work was to provide planners, technicians and agencies with detailed understanding of the potential and shortcomings of modelling and DSS currently available on the market and used in research. Finally we presented an application to test a transport system simulation through a DSS by implementing a microscopic DTA model to support evacuation planning. The aim of the application was to test the response capabilities of a DSS to help validate procedures to be implemented in the event of emergency evacuation.

\section{References}

[1] Russo, F., Vitetta, A., Risk evaluation in a transportation system. In International journal of sustainable development and planning, no. 1, pp. 170-191, 2006.

[2] Russo, F., Rindone, C., Safety of users in road evacuation: the logical framework approach in evacuation planning. In Urban Transport XIV, Brebbia C.A. (ed.), WIT Press, pp. 751-760, 2008.

[3] Russo, F., Chilà, G., Safety of users in road evacuation: RP vs. SP surveys in demand analysis. In Urban Transport XIV, Brebbia C.A. (ed.), WIT Press, pp. 703-713, 2008.

[4] Vitetta, A., Musolino, G., Marcianò, F. A., Safety of users in road evacuation: supply and demand-supply interaction models for users. In Urban Transport XIII. Brebbia C.A. (ed.), WIT Press,, pp. 783-792, 2007.

[5] Vitetta, A., Musolino, G., Marcianò, F. A., Offerta e interazione tra domanda e offerta nei sistemi di trasporto in condizioni di emergenza. Modelli e metodi per la simulazione, applicazione ad un caso reale. FrancoAngeli, Milano, 2007.

[6] Vitetta, A., Musolino, G., Marcianò, F. A., Safety of users in road evacuation: calibration of cost functions and simulation. In Urban Transport XIV. Brebbia C. A. (ed.), WIT Press, pp. 715-726, 2008.

[7] Vitetta, A., Quattrone, A., Polimeni, A., Safety of users in road evacuation: algorithms for path design of emergency vehicles. In Urban Transport XIV Brebbia C.A (ed.), WITPress, pp. 727-738, 2008.

[8] Di Gangi, M., Velonà, P., Catanzariti, A., Safety of users in road evacuation: some enhancement in modelling pedestrian evacuation of a building. In Urban Transport XIV Brebbia C.A (ed.), WITPress, pp. 739$750,2008$.

[9] Hobeika, A.G., and B. Jamei. MASSVAC: A model calculating evacuation times under natural disasters. In Computer Simulation in emergency Planning, $15 \mathrm{~N}^{\circ}$ 1. Society for Computer Simulation, La Jolla, California, 1985.

[10] Liu, H. X., X. He, and X. Ban. A Cell-Based Many-to-One Dynamic System Optimal Model and Its Heuristic Solution Method for Emergency Evacuation. In Transportation Research Board 86th Annual Meeting CDROM, Washington, D.C., 2007. 
[11] Cova, T. J., and J. P. Johnson. Microsimulation of neighborhood evacuations in the urban-wildland interface. In Environ. Plan. B: Plan. Des., 34, 2002, pp. 2211-2229.

[12] Mc Ghee, C.C., and M.C. Grimes. An operational analysis of the Hampton roads hurricane evacuation traffic control plan. In Transportation Research Board 86th Annual Meeting CD-ROM, Washington, D.C., 2007.

[13] Di Gangi, M., and P. Velonà. Analisi e gestione di una rete di trasporto in condizioni di emergenza mediante procedure di mesosimulazione. In: Evacuazione dei sistemi urbani. Metodi quantitativi per l'analisi di un sistema di trasporto in condizioni di emergenza. Russo F. (ed.), FrancoAngeli, Milano, 2004, pp. 107-128.

[14] Pel, A. J., and M. C. J. Bliemer. Evacuation Plan Evaluation: Assessment of Mandatory and Voluntary Vehicular Evacuation Schemes by means of an Analytical Dynamic Traffic Model. In TRB 87th Annual Meeting Compendium of Papers DVD, Washington, D.C., 2008.

[15] Hardy, M, Wunderlich, K, Evacuation Management Operations (Emo) Modelling Assessment: transportation modelling inventory. 2007. Available from: http://www.its.dot.gov/its_publicsafety/emo/emo.pdf. Accessed February 2009.

[16] Houston N., Routes to Effective Evacuation planning primer series: Using Highways during notice Evacuations operations. 2006. Available from: http://ops.fhwa.dot.gov/publications/evac_primer/primer.pdf. Accessed February 2009.

[17] INRO Consultants INC., EMME/2 (vers. 9) User's Manual. 1999.

[18] Caliper Corporation, TransCAD (vers. 4.4) User's Guide. 2000.

[19] C.S.S.T. s.p.a. \& ELASIS, MT Model (vers. 4.1) Manuale Utente, 1997.

[20] PTV Vision, VISUM (vers. 7.50) User Manual. 2001.

[21] OMNITRANS Manual. 2008.

[22] CITILABS, Cube Avenue. Available from: http://www.citilabs.com /cube_avenue.html. Accessed February 2009.

[23] Mahmassani, H. S., Sbayti, H., Zhou, X., DYNASMART-P (vers. 1.1) User's Guide. 2004.

[24] Caliper Corporation, TransModeler (vers. 1.1) User's Guide. 2006

[25] MIT Intelligent Transportation Systems Program, DynaMIT. Available from: http://mit.edu/its/dynamit.html. Accessed February 2009.

[26] ,Di Gangi, M., Catanzariti, A., DSS SICURO Manuale d'Uso, 2007.

[27] Transport Simulation System, AIMSUN2 v3.3 User's Manual. 1999.

[28] Van Aerde, M. \& Assoc., INTEGRATION (vers. 2.30) User's Guide. 2000.

[29] MIT Intelligent Transportation Systems Program, MITSIMLab User's Guide. 2002.

[30] Quadstone; Paramics V5.0. Available from: http://www.paramics.it /v5.1.htm. Accessed February 2009.

[31] PTV Vision, VISSIM (vers. 3.70) User Manual. 2003. 